\title{
Activation of FXR by obeticholic acid induces hepatic gene expression of SR-BI through a novel mechanism of transcriptional synergy with the nuclear receptor LXR
}

\author{
BIN DONG ${ }^{1}$, AMAR B. SINGH ${ }^{1}$, GRACE L. GUO ${ }^{2}$, MARK YOUNG $^{3}$ and JINGWEN LIU ${ }^{1}$ \\ ${ }^{1}$ Department of Veterans Affairs, Palo Alto Health Care System, Palo Alto, CA 94304; \\ ${ }^{2}$ Department of Pharmacology and Toxicology, School of Pharmacy, Rutgers University, Piscataway, NJ 08854; \\ ${ }^{3}$ Mistral Therapeutics, San Diego, CA 92121, USA
}

Received September 21, 2018; Accepted February 13, 2019

DOI: 10.3892/ijmm.2019.4136

\begin{abstract}
The farnesoid X receptor (FXR) is known to regulate the gene expression of SR-BI, which mediates plasma high-density lipoprotein (HDL)-cholesterol uptake. Our previous study demonstrated that the activation of FXR by obeticholic acid (OCA) lowered plasma HDL-cholesterol levels and increased the hepatic mRNA and protein expression levels of SR-BI in hypercholesterolemic hamsters, but not in normolipidemic hamsters, suggesting that dietary cholesterol may be involved in the OCA-induced transcription of SR-BI. In the present study, a functional 90-base-pair regulatory region was identified in the first intron of the SR-BI gene of hamster and mouse that contains a FXR response element (IR-1) and an adjacent liver X receptor (LXR) response element (LXRE). By in vitro DNA binding and luciferase reporter gene assays, it was demonstrated that FXR and LXR bind to their recognition sequences within this intronic region and transactivate the SR-BI reporter gene in a synergistic manner. It was also shown that mutations at either the IR-1 site or the LXRE site eliminated OCA-mediated gene transcription. Utilizing chow-fed hamsters as an in vivo model, it was demonstrated that treating normolipidemic hamsters with OCA or GW3965 alone did not effectively induce levels of SR-BI, whereas their combined treatment significantly increased the mRNA
\end{abstract}

Correspondence to: Dr Jingwen Liu, Department of Veterans Affairs, Palo Alto Health Care System, 3801 Miranda Avenue, Palo Alto, CA 94304, USA

E-mail: jingwen.liu@va.gov

Abbreviations: EMSA, electrophoresis mobility shift assay; FXR, farnesoid X receptor; FXRE, FXR response element; HPH, human primary hepatocytes; LXR, liver X receptor; LXRE, LXR response element; OCA, obeticholic acid; SR-BI, scavenger receptor class B type I; SRE, sterol regulatory element; SREBP, SRE-binding protein

Key words: farnesoid $\mathrm{X}$ receptor, obeticholic acid, SR-BI, liver $\mathrm{X}$ receptor, transcriptional synergy and protein levels of SR-BI in the liver. The study further investigated effects of FXR and LXR coactivation on the gene expression of SR-BI in human liver cells. The intronic FXRE and LXRE regulatory region was not conserved in the human SR-BI genomic sequence, however, higher mRNA expression levels of SR-BI were observed in human primary hepatocytes and HepG2 cells exposed to combined treatments of FXR and LXR agonists, compared with those in cells exposed to individual ligand treatment. Therefore, these results suggest that human SR-BI gene transcription may also be subject to concerted activation by FXR and LXR, mediated via currently unidentified regulatory sequences.

\section{Introduction}

The farnesoid X receptor (FXR) is a bile acid-activated nuclear receptor, which regulates bile acid synthesis and transport and the metabolism of cholesterol, the bile acid precursor (1-3). In mouse models, the activation of FXR attenuates the development of atherosclerosis and reduces plasma total cholesterol (TC) and high-density lipoprotein cholesterol (HDL-C). FXR is expressed at high levels in the liver, intestine and adrenal glands. FXR forms a heterodimer with retinoid $\mathrm{X}$ receptor (RXR) to modulate the expression of target genes by binding to DNA sequences referred to as FXR response elements (FXREs). The most common DNA-binding motif bound by FXR is the highly conserved inverted repeat separated by 1 nucleotide (IR-1: G/AGGTGA A TAACCT) (4-8).

Scavenger receptor class B type I (SR-BI) is a physiologically relevant HDL receptor and serves distinct roles in plasma HDL metabolism and transhepatic cholesterol efflux in preclinical animal models and in humans (9-12). Previous studies have shown that the activation of FXR by its natural ligand, chenodeoxycholic acid (4), or synthetic ligands, including obeticholic acid (6E-CDCA; INT-747;OCA;OCALIVA ${ }^{\mathrm{TM}}$ ) (13), which is approved by the Food and Drug Administration for treating primary biliary cholangitis, increases the hepatic expression of SR-BI, which has been considered the primary mechanism responsible for FXR-mediated reductions in plasma HDL-C (14). Of note, different regulatory mechanisms for the FXR-mediated induced gene expression of SR-BI have 
been suggested. One study reported that the activation of FXR by synthetic ligand GW4064 increased the protein levels of the hepatocyte nuclear factor $4 \alpha(\mathrm{HNF} \alpha)$, transcription factor, which led to transcriptional activation of the SR-BI gene via $\mathrm{HNF} 4 \alpha$-binding sequences embedded in the promoter region and intronic sequences of the murine SR-BI gene (15). Two other studies identified functional FXR binding sites (IR-1s) in the first intron of the mouse SR-BI gene, which mediate the FXR-induced expression of SR-BI in mice $(4,16)$. Furthermore, it was reported that treating HepG2 cells with GW4064 increased the mRNA levels of SR-BI. This effect was linked to the binding of FXR to a putative FXRE site (DR8) in the promoter region of the human SR-BI gene (17).

Our previous investigations conducted in hamster models have shown that the activation of FXR by obeticholic acid (OCA) increases the hepatic expression of SR-BI and accelerates the removal of circulating HDL-C with increased fecal cholesterol excretion in hamsters fed a high fat and high cholesterol diet (18). It was observed that, in hamsters fed a normal chow diet, OCA treatment induced the expression of small heterodimer partner (SHP) and other typical FXR-target genes; however, it did not increase the expression of SR-BI nor enhance transhepatic cholesterol output. These previous findings suggest that dietary cholesterol may be involved in OCA-induced SR-BI transcription in hamsters.

Liver X receptors (LXRs) are ligand-activated receptors that act as cholesterol sensors (19). LXRs form an obligate heterodimer with RXR, and the heterodimer binds to LXR response elements (LXREs) in LXR target genes. LXREs consist of direct repeats of the consensus half-site sequence AGGTCA separated by four nucleotides (DR4) $(6,20)$. In mice, the activation of LXRs by endogenous ligands of oxidized cholesterol derivatives and pharmaceutical agonists, including GW3965, leads to induction of genes involved in reverse cholesterol transport and mobilization of cholesterol, including the ATP binding cassette (ABC) transporter genes Abca1, Abcg1, Abcg5, Abcg8, and genes involved in bile acid synthesis, including Cyp7A1 $(21,22)$. However, the mRNA levels of Sr-b1 in the liver were not upregulated by the LXR agonist in chow-fed mice (23), nor in normolipidemic hamsters (18).

In the present study, the involvement of LXR in the OCA-induced upregulated hepatic expression of SR-BI was examined. By conducting genomic sequence analysis and direct DNA binding assays, a highly conserved regulatory region was identified in the first intron of the hamster SR-BI gene, which contains a functional FXR response element IR-1 motif and an LXRE site separated by 57 base pairs (bp). Luciferase reporter gene activity assays demonstrated the functional involvement of this critical regulatory region in SR-BI gene transcription upon activation of FXR and LXR in a synergistic manner. Experiments in normolipidemic hamsters showed that hepatic gene expression of SR-BI was not effectively activated by individual treatment with OCA nor the LXR agonist GW3965, whereas the co-activation of FXR and LXR by the combined treatment resulted in significant increases in hepatic mRNA and protein levels of SR-BI. Taken together, the findings demonstrated the unprecedented concerted activation of SR-BI gene transcription by the two nuclear receptors, FXR and LXR, which are master regulators of bile acid and cholesterol metabolism.

\section{Materials and methods}

Cells and reagents. Human hepatoma HepG2 cells were obtained from American Type Culture Collection (Manassas, VA, USA). Human primary hepatocytes (HPH) were obtained from Invitrogen; Thermo Fisher Scientific, Inc. (Waltham, MA, USA). 6E-CDCA was purchased from Abcam (Cambridge, MA, USA). GW4064 and GW3965 were purchased from Tocris Bioscience (Bristol, UK). OCA was provided by Intercept Pharmaceuticals, Inc. (New York, NY, USA). The expression plasmid for human FXR $\alpha$ was provided by Dr Timothy F. Osborne from Sanford Burnham Prebys Medical Discovery Institute (La Jolla, CA, USA). Expression plasmids for human RXR $\alpha$ and LXR $\alpha$ were obtained from GenScript Corporation (Piscataway, NJ, USA).

Cloning of hamster FXR responsive intronic sequences and construction of luciferase reporters. Hamster genomic sequences were first analyzed (NW_004801705. 1:3779075-3853729 Mesocricetus auratus isolate Golden Hamster female 1 unplaced genomic scaffold, MesAur1.0 scaffold00102, whole genome shotgun sequence) and three segments were identified, termed A, B and C, in the first intron of the SR-BI gene that are homologous to the IR-1-containing regions of the mouse SR-BI gene (4). Fragments A, B and C are located from $+9,659$ to $+10,483$, from $+19,849$ to $+20,687$, and from $+33,252$ to $+34,052$ relative to the translation start codon, respectively. All fragments were amplified from hamster genomic DNA (50 ng) by polymerase chain reaction (PCR). The thermocycling conditions were as follows: Dual-lock DNA polymerase, $95^{\circ} \mathrm{C}$ for $2 \mathrm{~min}$ (1 cycle); denaturation at $95^{\circ} \mathrm{C}$ (30 cycles); annealing at $60^{\circ} \mathrm{C}$ for $1 \mathrm{~min}$ (30 cycles) followed by extension at $72^{\circ} \mathrm{C}$ for $10 \mathrm{~min}(1 \mathrm{cycle})$. The PCR fragment was initially cloned into the Topo 2.1 vector, and then subcloned into the pGL4.23 mini luciferase reporter vector to generate reporter plasmids, denoted as pGL4-ham-SRBI-site A, pGL4-ham-SRBI-site B and pGL4-ham-SRBI-site C, respectively. Following transformation and propagation in Escherichia coli, four independent clones of each reporter plasmid were sequenced to verify the sequence and orientation of the IR-1-containing fragment.

Using the QuikChange II XL Site-Directed Mutageneis kit (Agilent Technologies, Inc., Santa Clara, CA, USA), the site B FXRE mutant plasmid was produced by inducing mutations in four bases within the IR-1 site, and the site B LXRE mutant plasmid was produced by mutating three bases in the DR4 site. The cloning primers and mutated sequences are listed in Table SI.

Genomic DNA sequence alignment. MatInspector version 8.0 (24-26) was used to analyse the sequence of interest in the site $\mathrm{B}$ intronic region of different species.

Constructions of human SR-BI promoter luciferase reporters. For generation of the SR-BI promoter reporter, a DNA fragment of 1,106 bp covering the human SR-BI proximal promoter region between -869 and +237 relative to the transcription start site (TSS) was amplified from HepG2 genomic DNA and was cloned into the Topo 2.1 vector, followed by subcloning into pGL3-basic at the SacI and XhoI sites to yield the 
promoter reporter pGL3-hSRBI-1106. Similarly, the plasmid pGL3-hSRBI-1831 was made, which covered the genomic region between $-1,899$ and -68 . Following transformation and propagation in E. coli, four independent clones per reporter construct were sequenced to verify the sequence and orientation of the promoter fragment.

Luciferase reporter assay. The luciferase reporter assay was performed using the Firefly Luciferase Reporter ${ }^{\circledR}$ assay system (Promega Corporation, Madison, WI, USA) according to the manufacturer's protocol. The HepG2 cells were transfected with the designated reporter plasmids using FuGene 6 transfection reagent (Promega Corporation). As a control for differences in transfection efficiency, the pRL-TK plasmid encoding the Renilla luciferase gene was cotransfected with SR-BI reporter vectors and was used to normalize the firefly luciferase signal across all samples. Cells were cultured in MEM containing $0.5 \%$ fetal bovine serum overnight at $37^{\circ} \mathrm{C}$ and treated with GW4064 $(1 \mu \mathrm{M})$, OCA $(10 \mu \mathrm{M})$, or LXR agonist GW3965 $(5 \mu \mathrm{M})$ for $24 \mathrm{~h}$. At $\sim 48 \mathrm{~h}$ post-transfection or $24 \mathrm{~h}$ post-treatment with FXR and LXR agonists, the cells were lysed with $50 \mu 1$ of lysis buffer, followed by measurements of firefly luciferase and Renilla luciferase activities. The firefly luciferase activity was normalized to Renilla activity. Four wells were assayed for each condition. In certain transfection assays, plasmid pCMV- $\beta$-gal was co-transfected with the luciferase reporter (27). The cells were lysed in $50 \mu 1$ of reporter lysis buffer per well, of which $20 \mu \mathrm{l}$ of cell lysate was used to measure $\beta$-galactosidase activity according to the manufacturer's protocol using the $\beta$-Galactosidase Enzyme assay system (cat. no. E2000; Promega Corporation). The remaining $30 \mu \mathrm{l}$ of lysate was used to measure the firefly luciferase activity using the luciferase assay system. The absolute luciferase activity was normalized against $\beta$-galactosidase activity to correct for transfection efficiency.

Electrophoretic mobility shift assay (EMSA). Binding of FXR $\alpha /$ RXR $\alpha$ to the hamster SR-BI site B-FXRE region was assessed using the LightShift Chemiluminescent EMSA kit (Pierce; Thermo Fisher Scientific, Inc.) according to the manufacturer's protocol. Human recombinant proteins (FXR $\alpha, \mathrm{LXR} \alpha$ and RXR $\alpha$ ) were purchased from Active Motif (Carlsbad CA, USA). Briefly, a 5' biotin end-labeled probe identical to the 49-nucleotide region surrounding the putative FXRE element in the SR-BI intron 1 site $\mathrm{B}$ region was synthesized. The single stranded biotin-labeled probe, denoted SRBI-FXRE, was hybridized to an unlabeled complement, and 20 fmole of the double-stranded oligonucleotide was incubated for 20 min with purified human recombinant FXR $\alpha$ and RXR $\alpha$ proteins (100:100 ng; FXR $\alpha: \mathrm{RXR} \alpha$ ratio) mixture in vitro. The protein-DNA complex was resolved on 5\% TBE gels and transferred onto a nylon membrane. Following UV cross-linking and subsequent washing with $1 \mathrm{X}$ wash buffer (included in the kit), the biotin signal was visualized using chemiluminescence. For the competition experiments, a 100-fold higher concentration of unlabeled wild-type (WT) or FXRE-mutant oligos were incubated with the reaction mixture containing $\mathrm{FXR} \alpha / \mathrm{RXR} \alpha$ and the biotin-SRBI-FXRE probe. The binding of LXR $\alpha / \mathrm{RXR} \alpha$ to the SRBI-LXRE site was assessed using purified human recombinant LXR $\alpha$ plus $\mathrm{RXR} \alpha$ proteins utilizing the same experimental procedure as for the FXRE site. The sequences of the EMSA probes are listed in Table SI.

Animals, diet and drug treatment. All animal experiments were performed according to procedures approved by the VA Palo Alto Health Care System Institutional Animal Care and Use Committee (Palo Alto, CA, USA). Eight-week old male golden Syrian hamsters were purchased from Harlan Sprague Dawley (Indianapolis, IN, USA). The hamsters were housed (two animals/cage) under controlled temperature $\left(22^{\circ} \mathrm{C}\right)$ and lighting (12-h light/dark cycle). The animals had free access to autoclaved water and food (normal chow). OCA or GW3965 was suspended in $0.5 \%$ carboxyl-methyl cellulose (vehicle) and sonicated at $4^{\circ} \mathrm{C}$ in a Bioruptor 300 instrument (Diagenode, Inc., Denville, NJ, USA) for 4-6 cycles of $30 \mathrm{sec}$ ON: $30 \mathrm{sec}$ OFF on a 'medium' setting with intermittent vortexing.

A total of 20 hamsters, fed a normal chow diet, were divided into four groups ( $n=5$ per group) and were gavaged once per day at 9:00 a.m. for 10 days with vehicle, or $10 \mathrm{mg} / \mathrm{kg} /$ day OCA, or GW3965 twice a day $(30 \mathrm{mg} / \mathrm{kg}$ BID, 9:00 a.m. and 5:00 p.m.), or both in combination. Following the final treatment, all animals were sacrificed for collection of 16-h fasting serum and liver tissues at 9:00 a.m. of day 11. The livers were immediately removed, weighed, cut into small pieces, and stored at $-80^{\circ} \mathrm{C}$ for RNA and protein isolations and lipid extraction. Fecal samples were collected over a $24 \mathrm{~h}$ period after 9 days of treatment. Health parameters, including body weight and food intake, were monitored and recorded throughout the experimental duration. Fig. S1 shows the experimental protocol.

Measurement of serum lipids. Standard enzymatic methods were used to determine the TC and HDL-C with kits purchased from Stanbio Laboratory (Boerne, TX, USA).

Measurement of hepatic lipids. The frozen liver tissue (50 mg) were homogenized in $1 \mathrm{ml}$ chloroform/methanol (2:1). Following homogenization, lipids were extracted by rocking the samples overnight at room temperature, followed by centrifugation at 2,300 $\mathrm{x}$ g for $10 \mathrm{~min}$ at room temperature. The supernatant was transferred to a new tube and mixed with $0.2 \mathrm{ml} 0.9 \%$ saline. The mixture was then centrifuged at $300 \mathrm{x} \mathrm{g}$ for $5 \mathrm{~min}$ at room temperature and the lower phase containing the lipids was transferred into a new tube. The lipid phase was dried overnight and dissolved in $0.25 \mathrm{ml}$ isopropanol containing $10 \%$ Triton X-100. TC and triglycerides were measured using kits from Stanbio Laboratory.

Measurement of fecal total bile acids. The dried feces (20 mg) samples were homogenized and extracted in $1 \mathrm{ml}$ of $75 \%$ ethanol at $50^{\circ} \mathrm{C}$ for $2 \mathrm{~h}$ (18). The extract was centrifuged $(10,000,3 \mathrm{~min}$ at room temperature) and the supernatant was used to measure total bile acids using a kit from Diazyme, Poway, CA.

RNA isolation and reverse transcription-quantitative polymerase chain reaction $(R T-q P C R)$ analysis. Total RNA was extracted from liver tissue using the Quick RNA mini prep kit (Zymo Research Corp., Irvine, CA, USA) and was reverse-transcribed into cDNA. RT-qPCR analysis was 
performed with $50 \mathrm{ng}$ of cDNA template and specific primers using a SYBR-Green PCR kit $\left(5 \mu \mathrm{l}\right.$; Power $\mathrm{SYBR}^{\circledR}$-Green PCR Master mix) and an ABI Prism 7700 system (Applied Biosystems $^{\circledR}$; Thermo Fisher Scientific, Inc.) according to the manufacturer's protocols. The thermocycling conditions were as follows: UDG activation, $50^{\circ} \mathrm{C}$ for $2 \mathrm{~min}$ ( 1 cycle); Dual-lock DNA polymerase, $95^{\circ} \mathrm{C}$ for $2 \mathrm{~min}(1 \mathrm{cycle})$; denaturation, $95^{\circ} \mathrm{C}$ for $15 \mathrm{sec}$ ( 40 cycles); annealing, $60^{\circ} \mathrm{C}$ for $1 \mathrm{~min}(40$ cycles) and extension, $72^{\circ} \mathrm{C}$ for $10 \mathrm{~min}$ ( 1 cycle). The RT-qPCR primers $(400 \mathrm{nM})$ for each gene are listed in Table SI. Target mRNA expression in each sample was normalized to the housekeeping gene GAPDH. The $2^{-\Delta \Delta C q}$ method was used to calculate relative mRNA expression levels (28).

Western blot analysis. Approximately $50 \mathrm{mg}$ of frozen liver tissue was homogenized in $0.3 \mathrm{ml}$ RIPA buffer containing $1 \mathrm{mM}$ PMSF and protease inhibitor cocktail (Roche Diagnostics, Basel, Switzerland). Protein concentration was determined via a BCA assay kit (Pierce; Therm Fisher Scientific, Inc.). The homogenate proteins $(75 \mu \mathrm{g})$ from individual liver samples were resolved by SDS-PAGE $\left(10 \%\right.$ Criterion $^{\mathrm{TM}}$ Tris-HCl Protein Gel (Bio-Rad Laboratories, Inc., Hercules, CA, USA) and transferred onto nitrocellulose membranes; membranes were blocked with 5\% non-fat milk (cat. no. 170-6404; Bio-Rad Laboratories, Inc.). Anti-SR-BI antibody was purchased from Abcam (cat. no. Ab52629). Anti- $\beta$-actin antibody was purchased from Sigma-Aldrich; Merck KGaA (cat. no. A1978). Primary antibody was used at 1:1,000 dilution and secondary antibodies (cat. nos. 7074P2 and 7076P2) were used at 1:10,000 dilution. Immunoreactive bands of predicted molecular mass were visualized using SuperSignal West substrate (Thermo Fisher Scientific) and quantified using Alpha View software (version 3.3; Cell Biosciences, Inc., Santa Clara, CA, USA) with normalization by signals of $\beta$-actin.

Statistical analysis. GraphPad Prism 5 (GraphPad Software, Inc., La Jolla, CA, USA) was used to calculate averages and errors, generate graphs and perform statistical tests. Values are presented as the mean \pm standard error of the mean. Unless otherwise indicated, on passing Bartlett's test for equal variances, one-way analysis of variance with Tukey's multiple comparison test was used to compare groups of three or more. Student's unpaired two-tailed t-test was used for two-group comparisons. $\mathrm{P}<0.05$ was considered to indicate a statistically significant difference.

\section{Results}

Identification of a functional FXR response element (IR-1) in conjunction with an LXRE motif in the first intron of the hamster SR-BI gene. Our previous study conducted in hypercholesterolemic hamsters suggested that OCA increases the hepatic expression of SR-BI at the transcriptional level (18). However, how FXR activates SR-BI gene transcription in the hamster species remains to be elucidated.

To identify FXR response sequences in the hamster SR-BI gene, the present study first analyzed hamster genomic sequences and identified three segments, termed A, B and C, in intron 1 of the SR-BI gene, which are homologous to the IR-1 containing regions of the mouse SR-BI gene (4). The hamster site A and site B regions contained a putative IR-1 motif that are identical to the mouse IR-1 sequence, whereas the IR-1 site in segment $C$ of the mouse SR-BI gene was not found in the hamster sequence (Fig. 1A). The results of one representative experiment of luciferase reporter assays conducted in HepG2 cells are shown in Fig. 1B, and C shows the summarized results from four separate transfections. Together, these data demonstrate that the site B segment was responsive to FXR agonists, and reporter activities were induced $\sim 15$-fold by treating transfected cells with OCA or GW4064. By contrast, the luciferase activities of site $\mathrm{A}$ and site $\mathrm{C}$ were not induced by the activation of FXR over the control vector pGL4.23 with a minimal promoter containing only a TATA element. Therefore, these results identified the intron 1 site $\mathrm{B}$ region of the hamster SR-BI gene as the functional regulatory segment that responds to the ligand induced activation of FXR.

Analysis of the nucleotide sequence within this 824-bp segment of the site B intronic region using MatInspector software revealed the presence of an LXR binding site located 57 bp downstream from FXRE (Fig. 2A). To assess the functionality of LXRE, the responses of hamster SR-BI reporter genes to the LXR agonist GW3965 and FXR agonists were examined. The results showed that treating the transfected cells with LXR agonist GW3965 led to an increase of $~ 4$-fold in hamster site B reporter activity, without affecting site A and site $\mathrm{C}$ reporters (Fig. 2B). Although the 4 -fold increase in site B reporter activity induced by GW3965 was relatively modest when compared with the effects of FXR agonists OCA and GW4064, the stimulating effect of GW3965 on site B reporter activity was reproducible in multiple transfection assays.

Concerted activation of SR-BI gene transcription by FXR and $L X R$ via intron bindings. Sequence alignments of site $\mathrm{B}$ regions of the SR-BI gene of hamster, mouse, rat and human not only demonstrated that the FXRE and LXRE sequences are identical, but spacings between the two motifs are also strictly conserved among rodents (Fig. 3A). In contrast to rodents, this intronic region is not conserved in the human SR-BI gene; in particular, the FXRE sequence is absent in the human sequence.

The core nucleotide sequence of the FXRE site was mutated and the mutated plasmid was transfected along with the WT hamster site B reporter and the pGL4.23 basic vector individually into HepG2 cells. The transfected cells were treated separately with FXR agonists, LXR agonist or the combination of FXR and LXR agonists. The site B WT reporter activity was increased $\sim 10$-fold by GW4064 or OCA and 5-fold by GW3965; however, the coactivation of both nuclear receptors increased the reporter activity almost 30-fold, indicating a synergistic effect (Fig. 3B). Mutation in FXRE not only eliminated the induction by FXR agonists, but also almost eradicated the effect of GW3965 alone, as well as the combined inducing effects. Subsequently, the LXRE site was mutated and similar inhibitory effects were observed of LXRE mutation on the site B reporter activity in cells treated with GW3965, the FXR agonists or their combination (Fig. 3C). Taken together, these results suggest that the binding of FXR to its $c i s$-acting element IR-1 in the site B region depends on the interaction between activated LXR and the adjacent LXRE motif. 

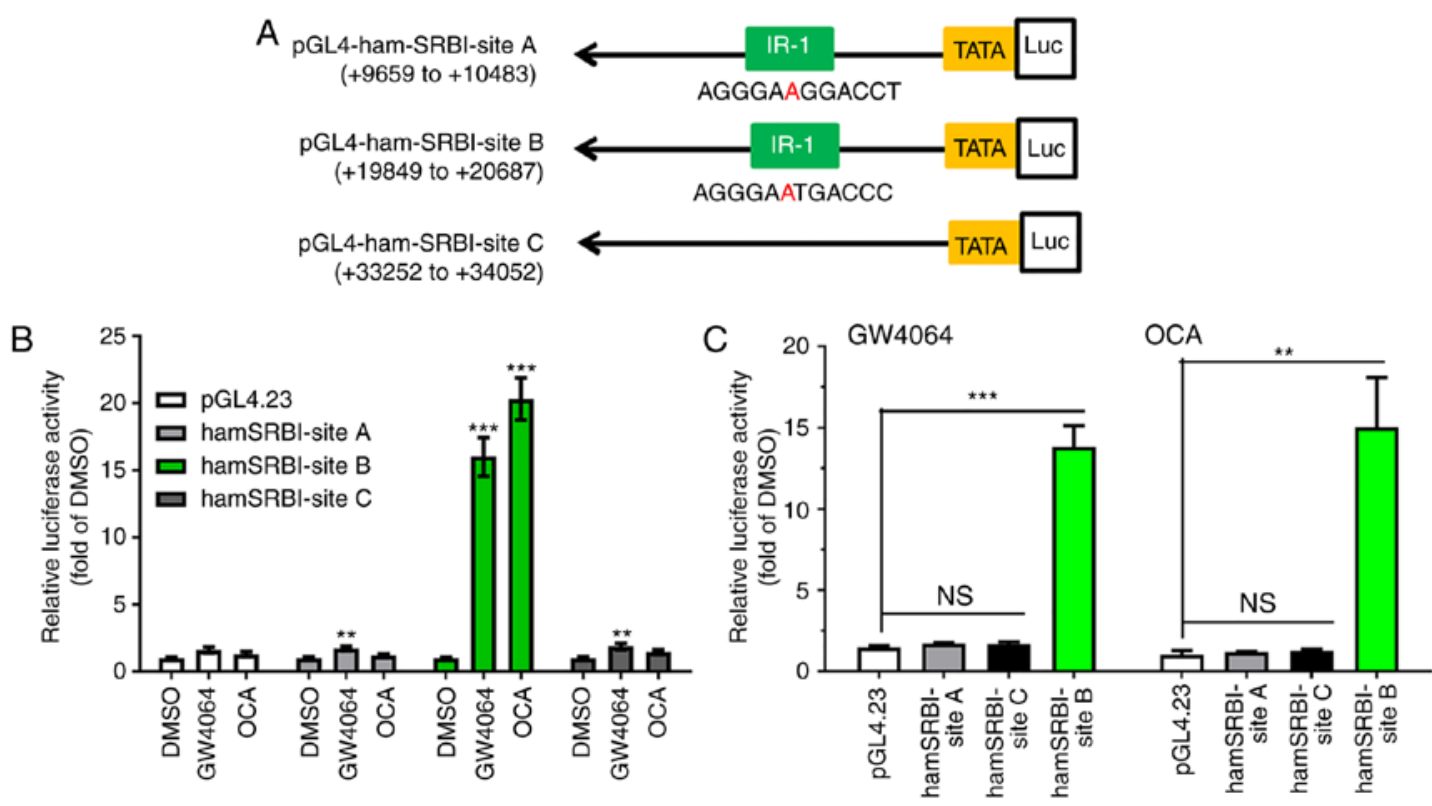

Figure 1. FXR activates the transcription of SR-BI via the FXRE motif located in the first intron of the hamster SR-BI gene. (A) Schematic presentation of luciferase reporter constructs with intronic sequences of the hamster SR-BI gene. (B) Reporter constructs were transiently cotransfected with pCMV- $\beta$-gal vector into HepG2 cells with four wells per condition. At 1 day post-transfection, cells were incubated in $0.5 \%$ fetal bovine serum medium overnight, followed by treatment with GW4064 $(1 \mu \mathrm{M})$ or OCA $(10 \mu \mathrm{M})$ for $24 \mathrm{~h}$. Cells were harvested, and the luciferase and $\beta$-gal activities were measured. Following normalization, relative luciferase activity of transfected cells treated with vehicle DMSO is expressed as 1 . Statistical significance among all groups was assessed by one-way ANOVA with Tukey's multiple comparison test. ${ }^{* *} \mathrm{P}<0.01$ and ${ }^{* * * *} \mathrm{P}<0.001$ between control and ligand-treated group. (C) Data are summarized results (mean \pm standard error of the mean) of four independent transfection assays. Following normalization, relative luciferase activity of transfected cells treated with vehicle DMSO is expressed as 1 . Statistical significance among all groups was assessed by one-way ANOVA with Tukey's multiple comparison test. ${ }^{* *} \mathrm{P}<0.01$ and ${ }^{* * *} \mathrm{P}<0.001$ compared with the inducing effects of OCA or GW4064 on control vector pGL4.23. FXR, farnesoid X receptor; FXRE, FXR response element; SR-BI, scavenger receptor class B type I; $\beta$-gal, $\beta$-galactosidase; OCA, obeticholic acid; ANOVA, analysis of variance; n.s., not significant.

In line with the hamster reporter activity data, it was observed that the site B segment in the mouse SR-BI reporter gene (4) was most responsive to the FXR and LXR individual treatments and the concerted activations (Fig. S2A and B).

It is well-demonstrated that FXR forms heterodimers with RXRa and binds the IR-1 motif to activate its target gene transcription (1). To determine whether the observed increase in site B reporter activity by FXR agonist treatment may be directly attributed to FXR binding to the putative FXRE sequence, the present study first examined the interaction of FXR with the SRBI-FXRE sequence by performing EMSA. Using biotin-labeled probes, the binding of purified FXR-RXR heterodimers to the 49-base pair region encompassing the hamster SR-BI site B IR-1 sequence was demonstrated (Fig. 4, lane 2). Competition with the WT unlabeled probe resulted in almost complete quenching of the binding with the biotin-labeled probe, whereas competition with an unlabeled probe harboring the mutant FXRE was less effective in repressing the binding of the FXR-RXR complex to the SRBI-FXRE probe (Fig. 4A, lanes 3 and 4).

Subsequently, EMSA was performed to assess the specific binding of LXR/RXR to the identified LXRE site within this intronic region. As shown in Fig. 4B, LXR/RXR was bound to the LXRE site with a high specificity. These results demonstrated the direct interactions of the SRBI-FXRE sequence with FXR and the SRBI-LXRE sequence with LXR in vitro.

In addition to the in vitro assay of direct DNA-protein interactions, the effects of the exogenous overexpression of nuclear receptors FXR $\alpha / \mathrm{RXR} \alpha$ and LXR $\alpha / \mathrm{RXR} \alpha$ on SR-BI reporter gene transcription were examined. A previous study reported that FXR binds to a putative FXRE site (DR8) that is located from -816 to -796 of the human SR-BI promoter region (17). In addition to the putative DR8 site, it was reported that the human SR-BI promoter contains a LXRE site located from $-1,001$ to -985 of the TSS (29). Therefore, the human SR-BI reporter construct pGL3-hSRBI-1109, containing the DR8 sequence, and pGL3-hSRBI-1898, containing both DR8 and LXRE sites, were constructed (Fig. S3A).

The hamster site B reporter and human SRBI-1893 reporter plasmids, and their respective control vectors, were separately cotransfected with the mock vector (pCMV-empty), or expression vectors for $\mathrm{FXR} \alpha / \mathrm{RXR} \alpha, \mathrm{LXR} \alpha / \mathrm{RXR} \alpha$, or FXR $\alpha / L X R \alpha / R X R \alpha$ into HepG2 cells, and the luciferase activity was measured $48 \mathrm{~h}$ post transfection (Fig. 4C). The overexpression of FXR and LXR had marginal effects ( 2-4-fold of the mock control) in elevating luciferase activities in cells transfected with the reporter control vector pGL4.23, pGL3-basic, and in cells transfected with the human SR-BI promoter. By sharp contrast, the luciferase activities in the hamster SRBI-site B-transfected cells were increased to 60-fold by FXR, 46-fold by LXR, and 210-fold by FXR and LXR co-expression compared with that in cells transfected with the mock vector. These data are in line with the findings of EMSA showing prominent bindings of FXR and LXR to the intronic regulatory region of the hamster SR-BI gene.

The responses of the human SR-BI promoter and the hamster reporter to ligand treatments were also examined (Fig. 4D and Fig. S3B and C). In contrast to the hamster site B reporter, human SR-BI promoter reporter activity was not significantly induced by OCA, GW3965 or the combination, suggesting that 
A
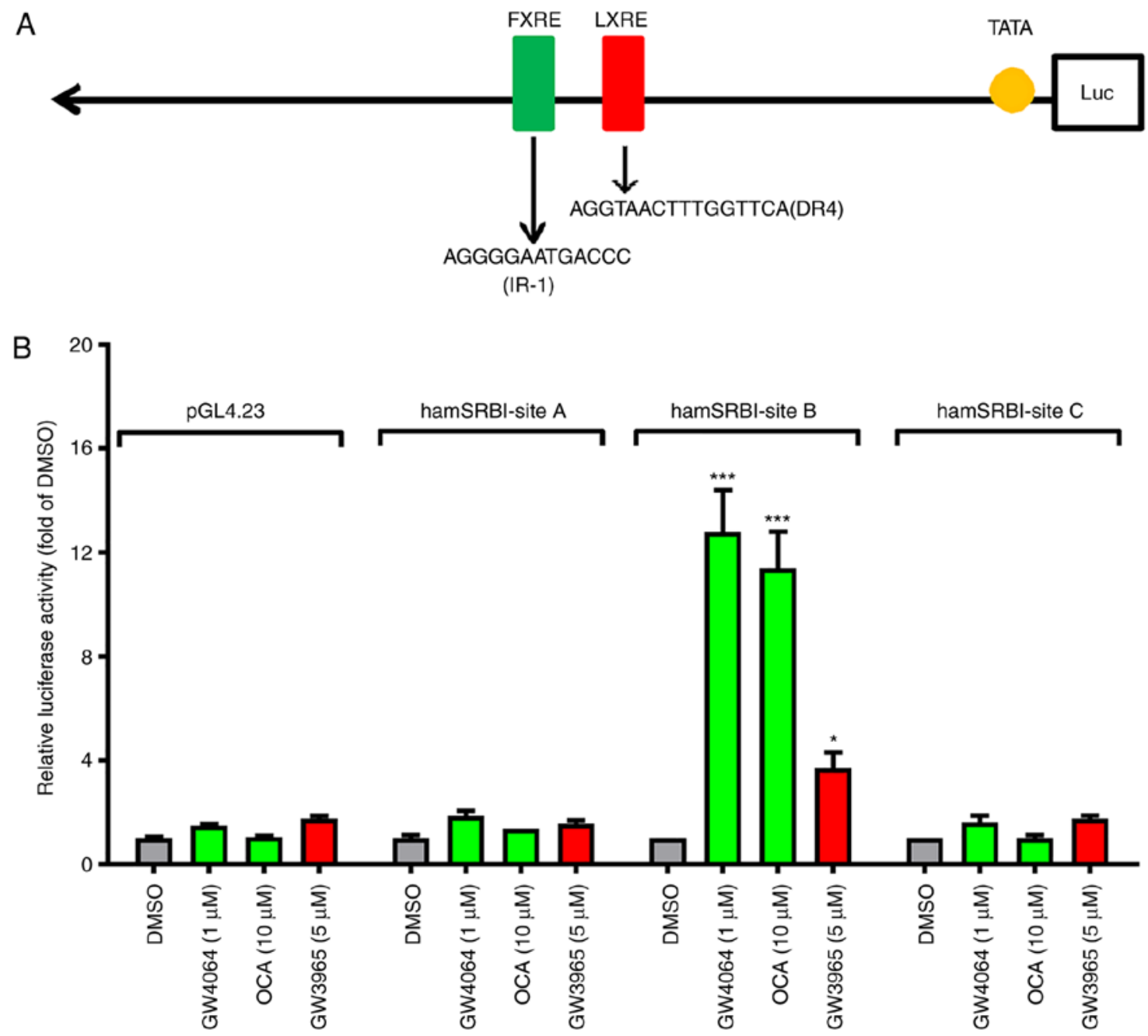

Figure 2. Identification of a novel LXRE site downstream pf FXRE in the hamster SR-BI gene. (A) Putative cis-regulatory elements located in the hamster site B luciferase reporter construct. (B) Reporter constructs were transiently cotransfected with pRL-TK vector into HepG2 cells. The following day, cells were cultured in MEM containing 0.5\% fetal bovine serum overnight and treated with GW4064 (1 $\mu \mathrm{M})$, OCA (10 $\mu \mathrm{M})$, or LXR agonist GW3965 (5 $\mu \mathrm{M})$ for $24 \mathrm{~h}$ prior to cell lysis. Data are presented as the mean \pm standard error of the mean of four replicates per treatment and are expressed as the ratio of firefly/Renilla activity from each sample where the relative luminescence from DMSO-treated cells is set to 1 . Statistical significance among all groups was assessed by one-way analysis of variance with Tukey's multiple comparison test. ${ }^{*} \mathrm{P}<0.05$ and ${ }^{* * *} \mathrm{P}<0.001$ compared with DMSO-treated samples. The data shown are representative of three separate transfection experiments. FXR, farnesoid X receptor; FXRE, FXR response element; LXR, liver X receptor; LXRE, LXR response element; SR-BI, scavenger receptor class B type I; OCA, obeticholic acid.

this proximal promoter region of the human SR-BI gene may not contain a high-affinity FXR binding sequence.

Subsequently, HPH were treated with OCA, GW3965 and their combination for $24 \mathrm{~h}$. RT-qPCR analysis showed that GW3965 treatment alone did not increase the mRNA levels of SR-BI, however, it potentiated the OCA-induced gene expression of SR-BI (Fig. 5A). No such synergistic effects were detected in the classical FXR target gene ABCB4 or the LXR target gene ABCA1. In addition to HPH, HepG2 cells were treated with FXR and LXR agonists and similar synergistic effects of OCA and GW3965 were observed on the gene expression of SR-BI (Fig. 5B). These results suggest that the gene expression of SR-BI in human liver cells can also be co-activated by FXR and LXR via unknown genomic sequences that are different from the regulatory elements found in the hamster and mouse SR-BI genes. this newly identified transcriptional synergy between FXR and LXR on the gene expression of SR-BI operates in vivo in the liver, chow-fed hamsters $(n=5$ per group) were treated with vehicle, $10 \mathrm{mg} / \mathrm{kg} / \mathrm{day}$ OCA, $30 \mathrm{mg} / \mathrm{kg} / \mathrm{day}$ GW3965 or OCA + GW3965 for 10 days. The body weight, food intake, liver weight and liver index were not significantly affected by the treatment (Fig. S4A-D). Examination of the protein expression of SR-BI in the liver by western blotting showed that, consistent with our previous study (18), OCA or GW3965 alone were not able to upregulate the liver expression of SR-BI in chow-fed hamsters. By contrast, the combined treatment significantly increased the protein levels of SR-BI to 1.75-fold of the vehicle control $(\mathrm{P}<0.001$; Fig. 6A and B). Hepatic gene expression analysis showed that the mRNA levels of SR-BI were only increased by the combined treatment to 1.8 -fold of the vehicle $(\mathrm{P}<0.001$; Fig. 6C). It was observed that the mRNA level of endothelial lipase was also elevated by the combination, whereas typical FXR target genes SHP and bile salt export pump (BSEP) 
Hamster CCACAGGGGAATGACCDTTTGGGAAGACAAAGGTGACATGGCACTGCCCTC- CCCCAG - GGTCCCAAGCACAGAGGTAACTTTGGTTCAT GG

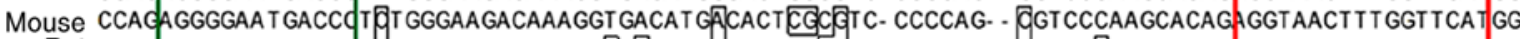

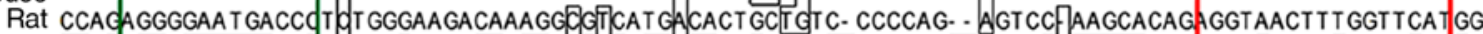

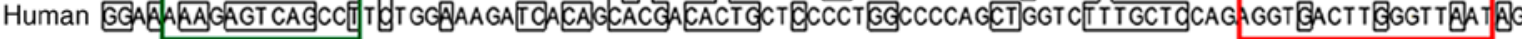

FXRE MU: $\underline{\text { ATTGGTATGACGC }}$

LXRE MU: ACCTAACTTTGGTTCA
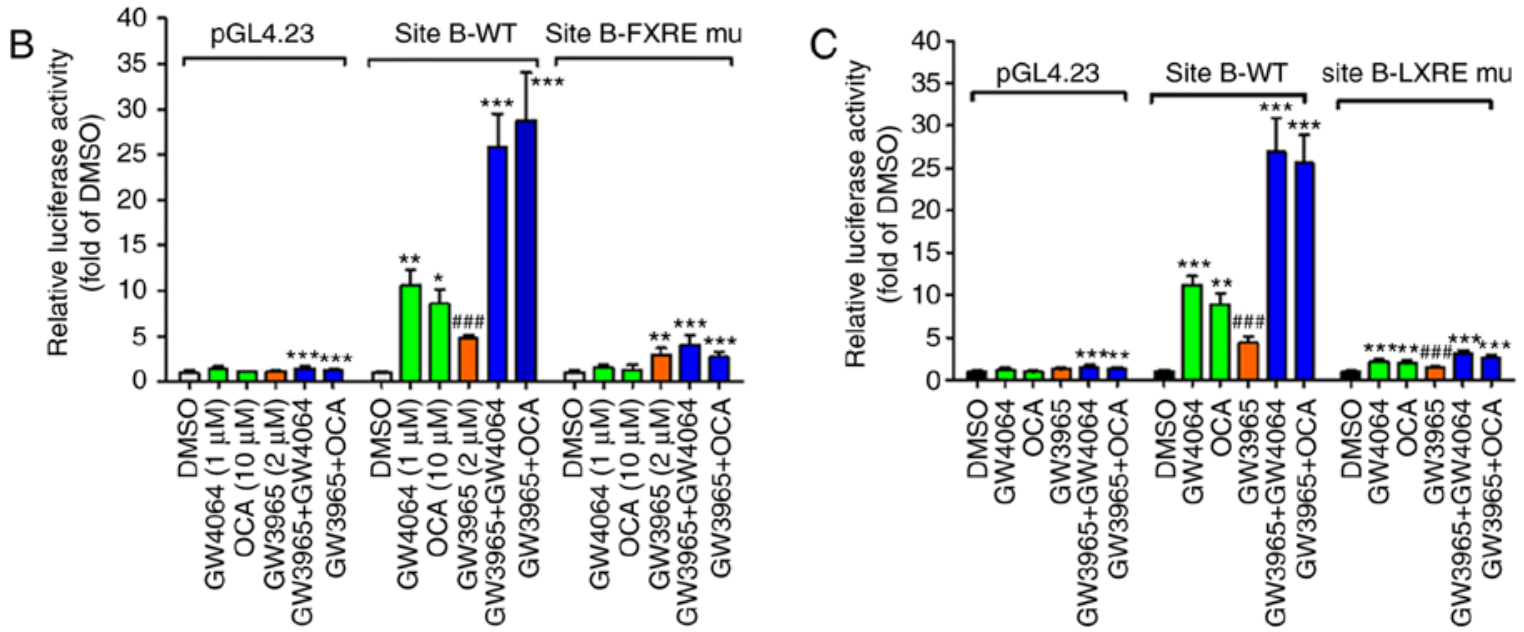

Figure 3. Novel FXR response element IR-1 and LXR response element DR4 mediate the transcription of SR-BI upon FXR and LXR coactivation. (A) Alignment of site B regions of intron one of the hamster, mouse, rat and human SR-BI gene. (B) WT site B reporter, FXRE-mu site B reporter and the control reporter pGL4.23 were transfected into HepG2 cells. The following day, cells were cultured in MEM containing $0.5 \%$ fetal bovine serum overnight and treated with GW4064 $(1 \mu \mathrm{M})$, OCA $(10 \mu \mathrm{M})$, GW3965 $(5 \mu \mathrm{M})$, GW3965 + GW4064, or GW3965 + OCA for 24 h. Data are presented as the mean \pm standard error of the mean of four replicates per treatment and are expressed as ratio of firefly/Renilla activity from each sample where the relative luminescence from DMSO-treated cells is set to 1. Statistical significance among all groups was assessed by one-way analysis of variance with Tukey's multiple comparison test. The data shown are representative of three separate transfection experiments. ${ }^{*} \mathrm{P}<0.05,{ }^{* *} \mathrm{P}<0.01$ and ${ }^{* * * *} \mathrm{P}<0.001$ compared with $\mathrm{DMSO}$; ${ }^{\# \# \#} \mathrm{P}<0.001$ compared with cotreated samples. (C) Luciferase activities in HepG2 cells transfected with the WT or LXRE-mu hamster site B plasmid and treated with compounds for $24 \mathrm{~h}$. Following normalization with Renilla activity, the relative luciferase activity (fold of DMSO) is indicated for each reporter plasmid. The data shown are representative of three separate transfection experiments. ${ }^{* *} \mathrm{P}<0.01$ and ${ }^{* * *} \mathrm{P}<0.001$ compared with DMSO; ${ }^{\# \# /} \mathrm{P}<0.001$ compared with cotreated samples. FXR, farnesoid X receptor; FXRE, FXR response element; LXR, liver X receptor; LXRE, LXR response element; SR-BI, scavenger receptor class B type I; WT, wild-type; mu, mutant; OCA, obeticholic acid.

were only responsive to OCA treatment. The mRNA levels of CYP7A1 in the hamster liver were repressed by OCA and GW3965 individual treatments, and the combined treatment produced the most marked inhibition. These in vivo results of the protein and mRNA expression measurements of SR-BI support the in vitro findings of a novel transcriptional mechanism for the upregulation of SR-BI by the integrated activation of FXR and LXR via this functional intronic region of the hamster SR-BI gene.

In addition to affecting gene expression in the liver, ligand treatments moderately altered cholesterol levels in the serum and liver tissue of the chow-fed hamsters. Serum TC and HDL-C levels were increased in the GW3965 group, which was not observed in the combination group (Fig. S5A and B). Hepatic TC contents were modestly increased in the livers of OCA-treated or GW3965-treated hamsters, as observed in previous studies $(18,30)$; however, hepatic cholesterol was not increased in the combination group (Fig. S5C).

Consistent with the suppression of the mRNA expression of CYP7A1, the fecal BA contents were reduced by $26 \%(\mathrm{P}<0.05)$ in the OCA-treated hamsters and were further reduced to almost half of that in the vehicle control $(\mathrm{P}<0.01)$ by the combinational treatment, despite no changes by GW3965 single treatment (Fig. S5D). Overall, these changes are consistent with the increased hepatic expression of SR-BI by FXR and LXR co-activation.

\section{Discussion}

FXR regulates several aspects of bile acid metabolism $(3,31)$, whereas LXR regulates cholesterol metabolism (19,32). Together, FXR and LXR maintain bile acid and cholesterol homeostasis by translating hormonal, metabolic and nutritional signals into changes in target gene expression (6,33-35). It is well recognized that both FXR and LXR partner with $\mathrm{RXR}$, but bind to distinct DNA recognition motifs and regulate different sets of metabolic genes. In certain cases, they can modulate the expression of the same gene with opposite effects. For example, in mice, the activation of FXR leads to marked suppression of the gene expression of Cyp7A1, inhibiting bile acid synthesis, whereas the gene expression of Cyp7A1 is induced in mice by LXR agonists to promote the synthesis of bile acids (36).

SR-BI is known as an FXR-modulated gene and the major physiological receptor for HDL-C. However, unlike other typical FXR target genes, including BSEP and SHP that are unfailingly induced by FXR agonists in liver cells across species, reports on the activation of FXR by various agonists on the gene expression of SR-BI have been inconsistent and conflicting in studies performed in cultured liver cells $(16,17)$ and in animals (14). Our previous study demonstrated that OCA upregulated the hepatic mRNA and protein expression of SR-BI in hamsters fed a cholesterol-enriched diet, but not in 
A

\begin{tabular}{|c|c|c|c|c|}
\hline & \multicolumn{5}{|c|}{ Biotin-SRBI-FXRE } \\
\hline FXR/RXRa & - & + & + & + \\
\hline Unlabeled FXRE WT & - & - & + & - \\
\hline Unlabeled FXRE MU & - & - & - & + \\
\hline
\end{tabular}

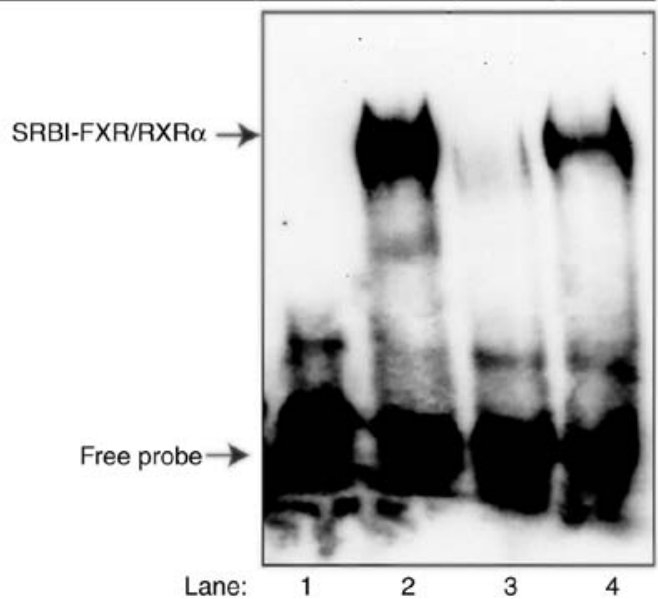

B

\begin{tabular}{|c|c|c|c|c|}
\hline & \multicolumn{4}{|c|}{ Biotin-SRBI-LXRE } \\
\hline LXR/RXRa & - & + & + & + \\
\hline Unlabeled LXRE WT & - & - & + & - \\
\hline Unlabeled LXRE MU & - & - & - & + \\
\hline
\end{tabular}

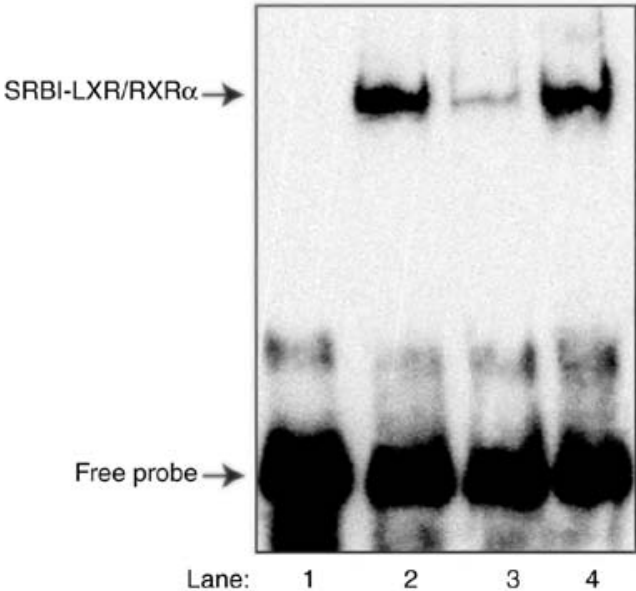

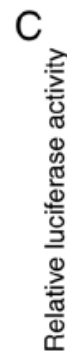

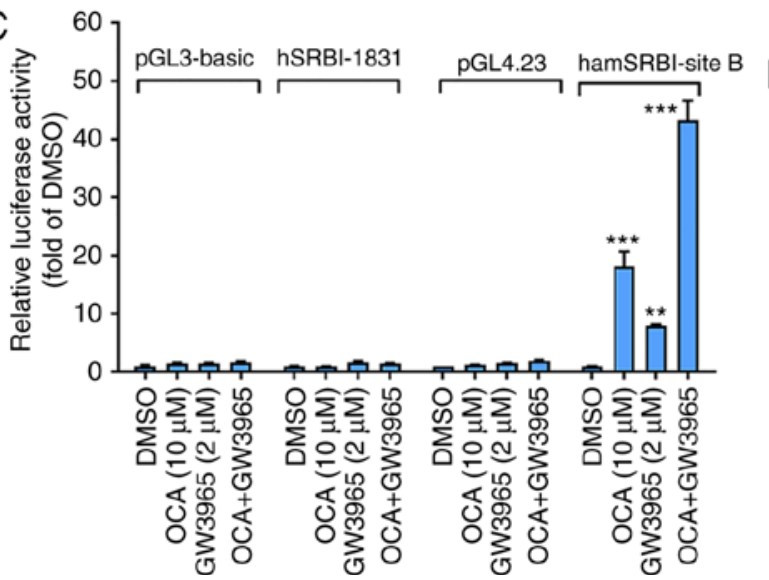

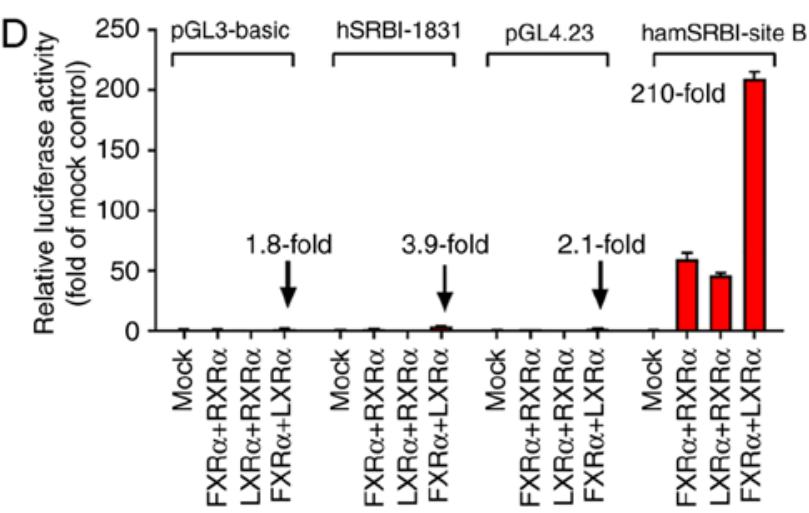

Figure 4. EMSA and reporter analyses of the association of FXR and LXR with the regulatory intronic region of site B segment of the hamster SR-BI gene. (A) EMSA to evaluate DNA-binding by FXR $\alpha / \mathrm{RXR} \alpha$. A biotin-5' end-labeled SRBI-FXRE probe was incubated without (lane 1) or with 100 ng of FXR $\alpha$ and $100 \mathrm{ng}$ of RXR $\alpha$ recombinant proteins in the absence (lane 2) or presence of 100-fold molar excess of unlabeled WT probe (lane 3) or MU probe (lane 4). The protein-DNA complex was resolved on 5\% TBE gels, transferred onto a nylon membrane and UV-crosslinked to the membrane prior to DNA visualization by avidin-chemiluminescent probe. The data shown are representative of three separate EMSA assays with comparable results. (B) EMSA to evaluate DNA-binding by LXR $\alpha /$ RXR $\alpha$. Biotin-5' end labeled SRBI-LXRE probe was incubated without (lane 1) or with 100 ng of LXR $\alpha$ and 100 ng of RXR $\alpha$ recombinant proteins in the absence (lane 2) or presence of 100-fold molar excess of unlabeled WT probe (lane 3) or MU probe (lane 4). The protein-DNA complex was resolved on 5\% TBE gels, transferred to a nylon membrane and UV-crosslinked prior to DNA visualization by avidin-chemiluminescent probe. The data shown are representative of two separate EMSA assays with comparable results. (C) HepG2 cells were cotransfected with pGL3-basic, pGL3-hSRBI-1831, pGL4.23, or hamster site B WT plasmid and indicated nuclear receptor expression plasmids or the control vector (pCMV-empty). At 2 days post-transfection, cell lysates were prepared. Following normalization with Renilla activity, the relative luciferase activity (fold of mock) is indicated for each reporter plasmid. (D) Human and hamster SRBI reporter vectors and their respective control vectors were transfected into HepG2 cells along with pRL-TK. The following day, cells were cultured in MEM containing $0.5 \%$ fetal bovine serum overnight and treated with OCA $(10 \mu \mathrm{M})$, GW3965 (2 $\mu \mathrm{M})$, or GW3965 + OCA for $24 \mathrm{~h}$ prior to cell lysis. Data are presented as the mean \pm standard error of the mean of four replicates per treatment and are expressed as ratio of firefly/Renilla activity from each sample where the relative luminescence from DMSO-treated cells is set to 1. Statistical significance among all groups was assessed by one-way analysis of variance with Tukey's multiple comparison test. ${ }^{* *} \mathrm{P}<0.01$ and ${ }^{* * *} \mathrm{P}<0.001$ compared with DMSO-treated samples. The data shown are representative of three separate transfection experiments. FXR, farnesoid X receptor; FXRE, FXR response element; LXR, liver X receptor; LXRE, LXR response element; SR-BI, scavenger receptor class B type I; WT, wild-type; mu, mutant; OCA, obeticholic acid.

hamsters fed a normal chow diet (18). It is now clear that FXR activates SR-BI gene transcription effectively in the presence of activated LXR via their adjacent recognition sequences located in the site B segment of the first intron of the hamster SR-BI gene. Notably, this intronic region containing FXRE and LXRE motifs is conserved in the hamster, mouse and rat SR-BI gene, but is not conserved in the human SR-BI gene (Fig. 3A).
The mutagenesis performed in the present study further showed that the disruption of LXRE attenuated FXR-mediated gene transcription, and, similarly, the ablation of FXRE IR-1 almost eliminated LXR-induced reporter activity. These data suggest a co-dependency of FXR and LXR binding to this regulatory region of the hamster SR-BI gene. By performing in vitro DNA binding assays, it was showed that FXR binds to the SRBI-FXRE sequence with high specificity, and the strong 

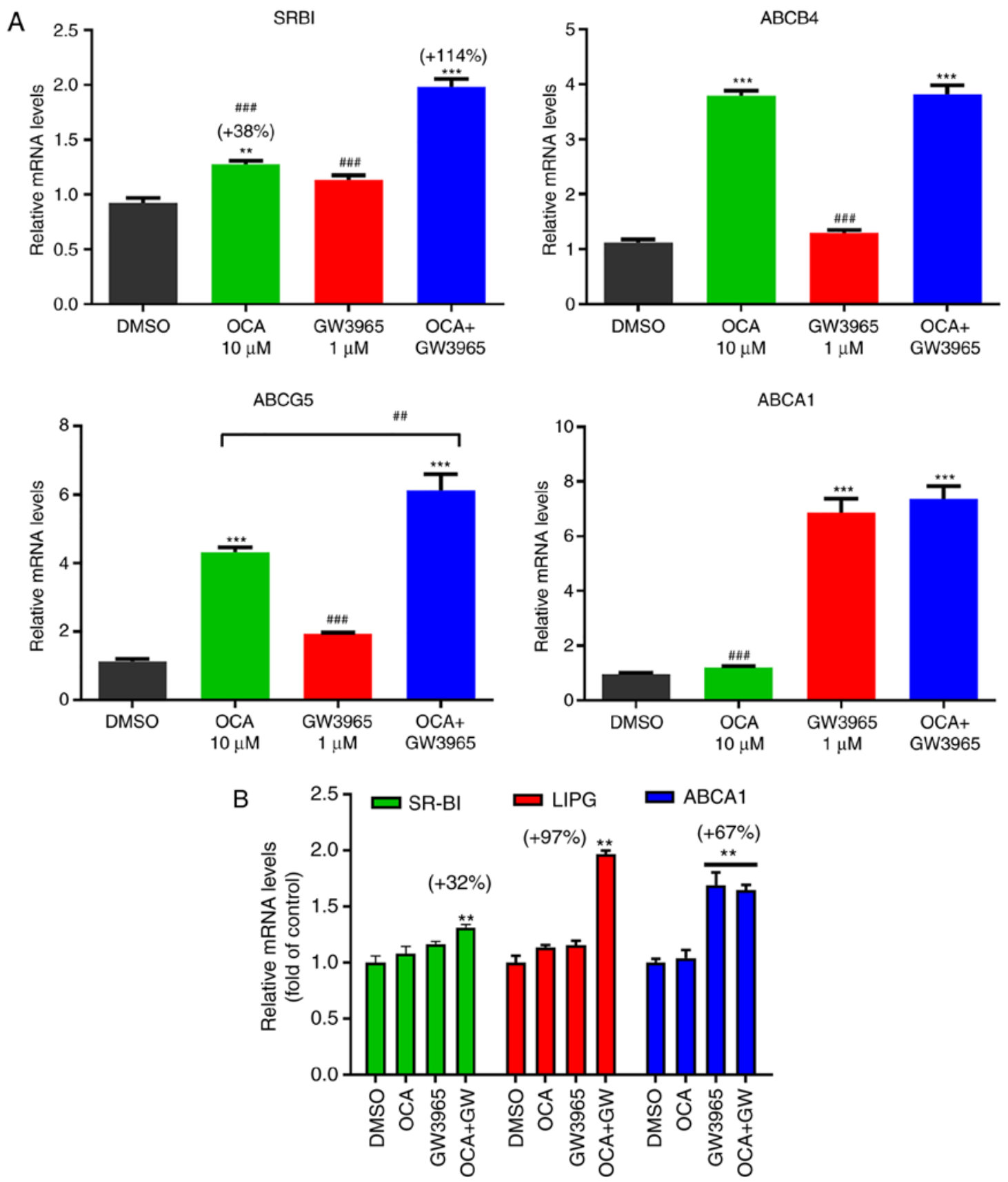

Figure 5. Synergistic activation of the gene expression of SR-BI by farnesoid X receptor and liver X receptor in HPH and HepG2 cells. (A) HPHs were treated with OCA $(10 \mu \mathrm{M})$ or GW3965 $(1 \mu \mathrm{M})$ or OCA + GW3965 for $24 \mathrm{~h}$ prior to isolation of total RNA. Triplicate wells were used in each treatment condition. RT-qPCR analysis was performed to measure relative mRNA levels of indicated genes with duplicate measurement of each cDNA sample. Statistical significance among all groups was assessed by one-way ANOVA with Tukey's multiple comparison test. ${ }^{* * *} \mathrm{P}<0.01$ and ${ }^{* * * *} \mathrm{P}<0.001$ compared with DMSO-treated samples; ${ }^{\# \#} \mathrm{P}<0.01$ and ${ }^{\# \# \#} \mathrm{P}<0.001$ compared with cotreated samples. (B) HepG2 cells in triplicate wells were cultured overnight in culture medium containing $0.5 \%$ fetal bovine serum, followed by treatment of OCA $(10 \mu \mathrm{M})$, GW3965 $(5 \mu \mathrm{M})$, or GW3965 + OCA for $24 \mathrm{~h}$. RT-qPCR analysis was performed to measure relative mRNA levels of indicated genes with duplicate measurement of each cDNA sample. One-way ANOVA with Tukey's multiple comparison test was used. HPH, human primary hepatocytes; OCA, obeticholic acid; GW, GW3965; SR-BI, scavenger receptor class B type I; ABC, ATP binding cassette; ANOVA, analysis of variance; RT-qPCR, reverse transcription-quantitative polymerase chain reaction.

binding of LXR to the newly identified SRBI-LXRE motif in this intronic region was confirmed. Due to the limitation of EMSA and the length of the biotin-labeled probe, it was not possible to examine the possibility of a direct interaction of FXR and LXR on this genomic region using the in vitro assay. However, the in vivo transactivation reporter assays clearly showed that the exogenous overexpression of FXR or LXR substantially increased the activities of the reporter containing the site B sequence without notable effects on the control reporter without the intronic sequence. In addition, the coexpression of FXR and LXR synergistically increased reporter activity. It was also shown that treating normolipidemic hamsters with OCA and the LXR agonist GW3965 individually did not effectively increase the expression of SR-BI, whereas the combined treatment significantly increased the mRNA and protein levels of SR-BI in liver tissues, which provided direct evidence that this synergistic activation of SR-BI gene transcription by FXR and LXR operates in liver tissue. Future 
A
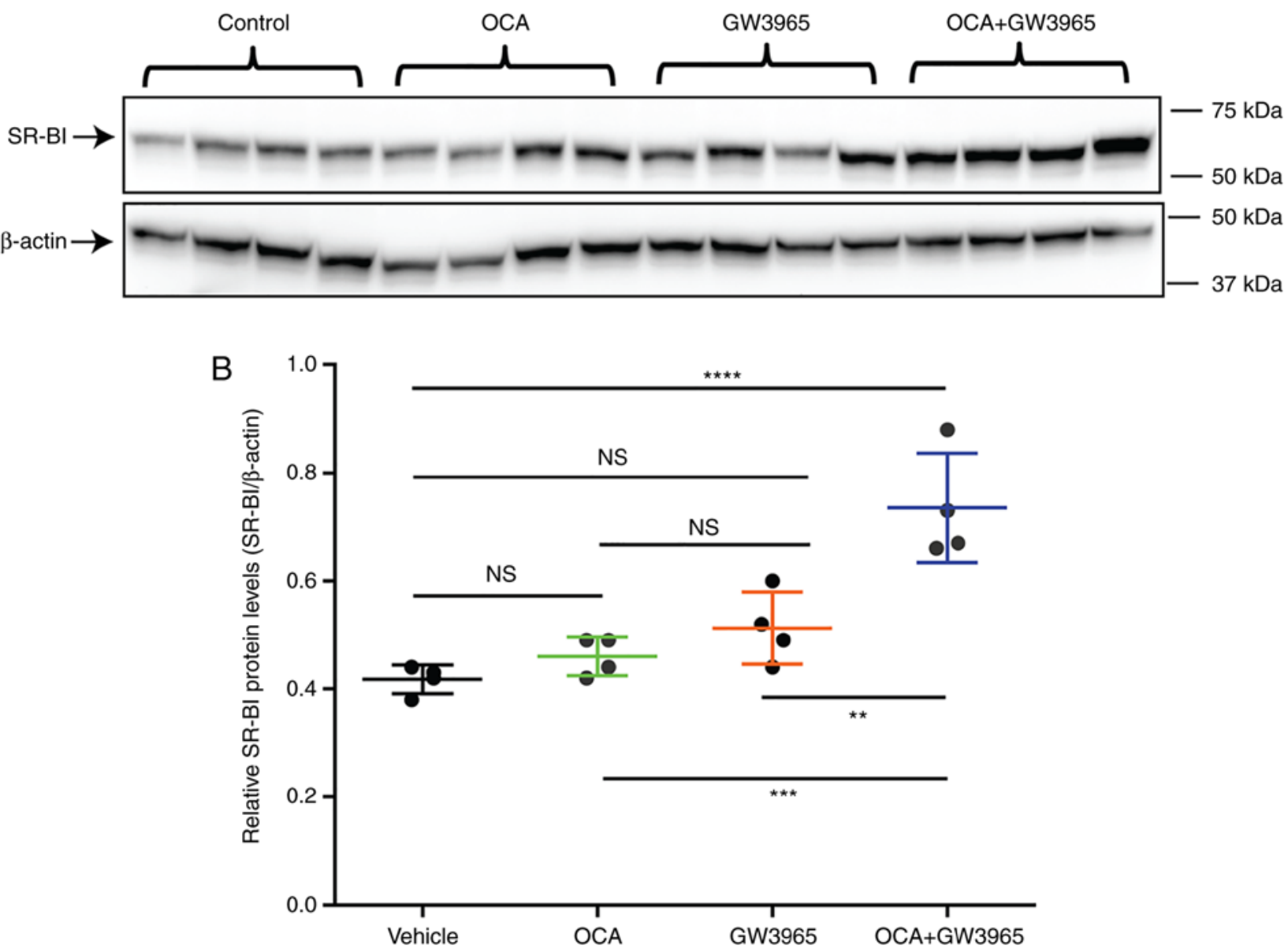
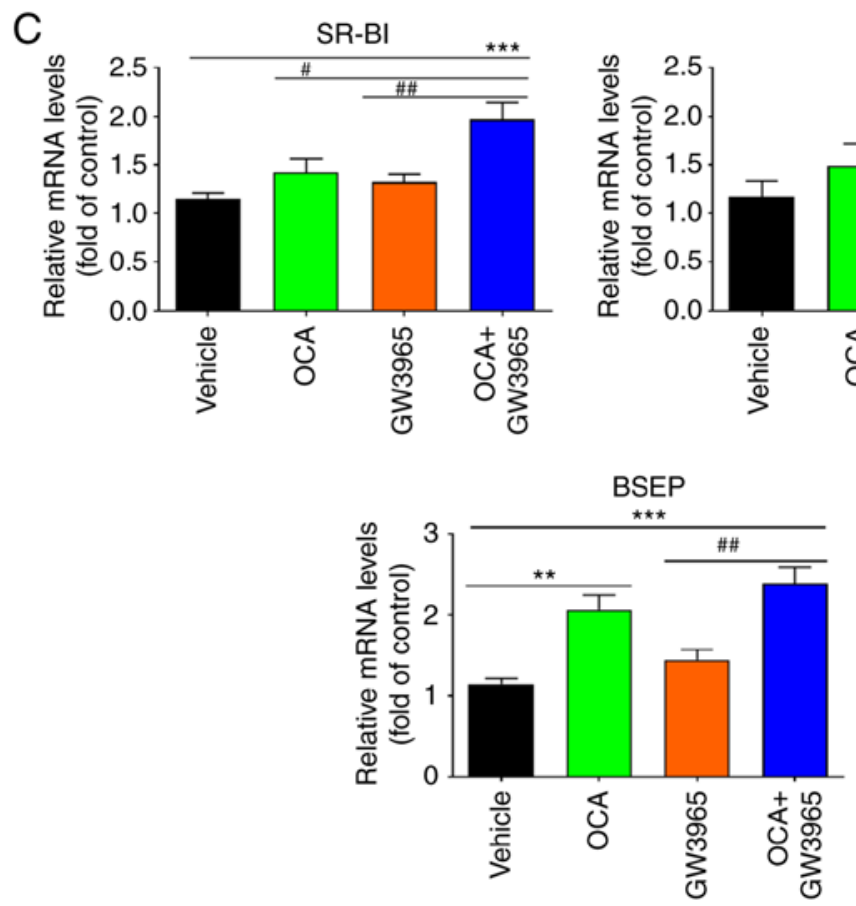

EL
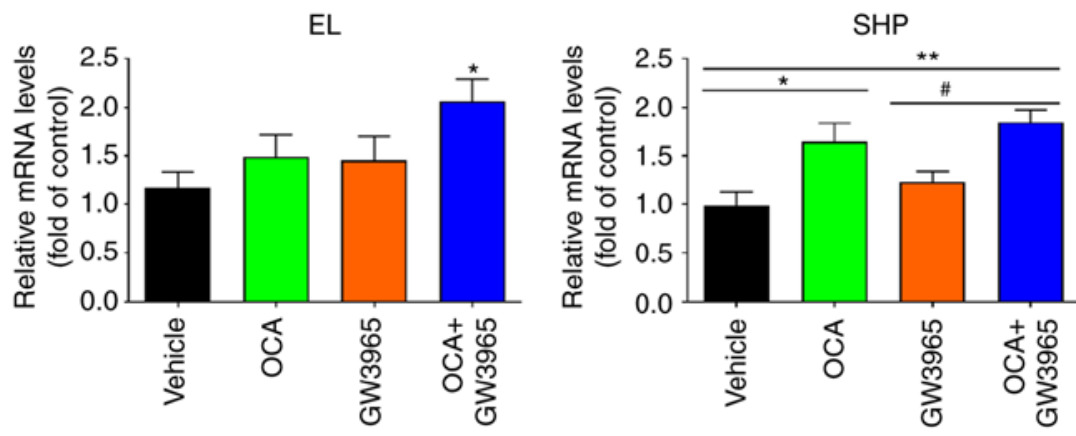

CYP7A1
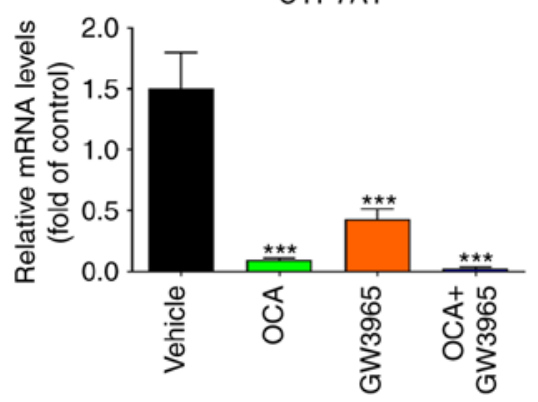

Figure 6. Synergistic activation of the gene expression of SR-BI by FXR and liver X receptor in hamster liver tissue. Hamsters fed a normal chow diet were treated with OCA $(10 \mathrm{mg} / \mathrm{kg} / \mathrm{day}, \mathrm{n}=5), \mathrm{GW} 3965(30 \mathrm{mg} / \mathrm{kg} / \mathrm{day}, \mathrm{n}=5)$, OCA + GW3965 (n=5), or vehicle control $(\mathrm{n}=5)$ for 10 days. Overnight fasting serum samples and liver tissues were collected. (A) Western blot analysis of the protein expression of SR-BI in liver samples from hamsters treated with vehicle, OCA, GW3965, and OCA + GW3965. Values are presented as the mean \pm standard error of the mean of four randomly chosen liver samples per group. (B) Protein quantification of western blots; protein levels of SR-BI were normalized to levels of $\beta$-actin. Statistical significance among all groups was assessed by one-way ANOVA with Tukey's multiple comparison test. ${ }^{* * * * *} \mathrm{P}<0.0001$ compared with the vehicle control group ${ }^{* *} \mathrm{P}<0.01$ and ${ }^{* * * *} \mathrm{P}<0.001$ compared with the combination group. $\mathrm{N}=4$ hamsters per group. (C) Reverse transcription-quantitative polymerase chain reaction analysis of hepatic gene expression of SR-BI and other FXR-modulated genes. Statistical significance among all groups was assessed by one-way ANOVA with Tukey's multiple comparison test. ${ }^{*} \mathrm{P}<0.05$, ${ }^{* *} \mathrm{P}<0.01$ and ${ }^{* * *} \mathrm{P}<0.001$ compared with the vehicle control group; ${ }^{*} \mathrm{P}<0.05$ and ${ }^{\# \#} \mathrm{P}<0.01$ compared with the combination group. $\mathrm{N}=5$ hamsters per group. FXR, farnesoid $\mathrm{X}$ receptor; OCA, obeticholic acid; SR-BI, scavenger receptor class B type I; ANOVA, analysis of variance; n.s., not significant. 
investigations are required to elucidate the precise mechanism underlying this observed cooperativity between FXR and LXR in the context of the SR-BI gene.

In conclusion, the present study identified a critical regulatory region in the hamster SR-BI gene that mediates the gene transcription of SR-BI upon FXR activation by OCA treatment under LXR-activated states. This occurs either by endogenous sterols in the cholesterol-enriched liver of HCHFD-fed hamsters or by synthetic agonist GW3965 cotreatment, an effect that increases cholesterol output and consequently overrides hepatic cholesterol accumulation caused by individual treatments. These novel findings provide a molecular explanation for the potent inducing effect of OCA on the expression of SR-BI in hypercholesterolemic hamsters. The present study identified a novel transcriptional mechanism for the expression of SR-BI through an integrated activation by FXR and LXR via intron bindings in hamsters and mice.

Regarding the human SR-BI gene, although the intronic regulatory region of SR-BI was not found, and the proximal promoter region up to $-1,899$ bp upstream of the TSS did not significantly respond to the activation of FXR or LXR, higher mRNA levels of SR-BI were detected in HPH and HepG2 cells upon OCA and GW3965 cotreatment, thereby suggesting that FXR and LXR may coactivate the human SR-BI gene through their interactions with currently unidentified regulatory sequences in the human SR-BI genome. Furthermore, it has been reported that the expression of SR-BI is regulated transcriptionally by other nuclear receptors, including peroxisome proliferator-activated receptor (PPAR) $\gamma$ and liver receptor homologue 1 (LRH-1) $(37,38)$. Therefore, it is possible that the activation of FXR may indirectly upregulate the expression of SR-BI in human liver cells via interacting with the PPAR pathway or LRH-1, and this interaction may be potentiated by LXR.

\section{Acknowledgements}

The authors would like to thank Dr Timothy F. Osborne from Sanford Burnham Prebys Medical Discovery Institute for providing the FXR $\alpha$ expression plasmid, and Dr Fredric B. Kraemer of Stanford University of Medicine, and Dr Progga Sen of the VA Palo Alto Health Care System for their critical review of the manuscript.

\section{Funding}

This study was supported by the Department of Veterans Affairs (Office of Research and Development, Medical Research Service; grant no. I01 BX001419, J.L.) and by a grant (grant no. 1R01AT006336-01A1, J.L) from the National Center for Complementary and Integrative Health.

\section{Availability of data and materials}

The authors declare that all supporting data are available within the article and its online supplementary files.

\section{Authors' contributions}

BD and ABS performed the experiments. GLG, MY and JL analyzed and interpreted the data. JL made substantial contributions to the design supervision of the present study, and wrote the manuscript. All authors reviewed the results and approved the final version of the manuscript.

\section{Ethics approval and consent to participate}

All animal experiments were performed according to procedures approved by the VA Palo Alto Health Care System Institutional Animal Care and Use Committee (Palo Alto, CA, USA).

\section{Patient consent for publication}

Not applicable.

\section{Competing interests}

MY was an employee and stockholder in Intercept Pharmaceuticals, Inc. at the time of contribution. The other authors have no competing interests.

\section{References}

1. Forman BM, Goode E, Chen J, Oro AE, Bradley DJ, Perlmann T, Noonan DJ, Burka LT, McMorris T, Lamph WW, et al: Identification of a nuclear receptor that is activated by farnesol metabolites. Cell 81: 687-693, 1995.

2. Lefebvre P, Cariou B, Lien F, Kuipers F and Staels B: Role of bile acids and bile acid receptors in metabolic regulation. Physiol Rev 89: 147-191, 2009.

3. Sinal CJ, Tohkin M, Miyata M, Ward JM, Lambert G and Gonzalez FJ: Targeted disruption of the nuclear receptor FXR/BAR impairs bile acid and lipid homeostasis. Cell 102: 731-744, 2000.

4. Li G, Thomas AM, Williams JA, Kong B, Liu J, Inaba Y, Xie W and Guo GL: Farnesoid X receptor induces murine scavenger receptor Class B type I via intron binding. PLoS One 7: e35895, 2012.

5. Laffitte BA, Kast HR, Nguyen CM, Zavacki AM, Moore DD and Edwards PA: Identification of the DNA binding specificity and potential target genes for the farnesoid X-activated receptor. J Biol Chem 275: 10638-10647, 2000.

6. Calkin AC and Tontonoz P: Transcriptional integration of metabolism by the nuclear sterol-activated receptors LXR and FXR. Nat Rev Mol Cell Biol 13: 213-224, 2012.

7. Thomas AM, Hart SN, Kong B, Fang J, Zhong XB and Guo GL: Genome-wide tissue-specific farnesoid $X$ receptor binding in mouse liver and intestine. Hepatology 51: 1410-1419, 2010.

8. Zhan L, Liu HX, Fang Y, Kong B, He Y, Zhong XB, Fang J, Wan YJ and Guo GL: Genome-wide binding and transcriptome analysis of human farnesoid $\mathrm{X}$ receptor in primary human hepatocytes. PLoS One 9: e105930, 2014.

9. Acton S, Rigotti A, Landschulz KT, Xu S, Hobbs HH and Krieger M: Identification of scavenger receptor SR-BI as a high density lipoprotein receptor. Science 271: 518-520, 1996.

10. Rigotti A, Trigatti BL, Penman M, Rayburn H, Herz J and Krieger M: A targeted mutation in the murine gene encoding the high density lipoprotein (HDL) receptor scavenger receptor class B type I reveals its key role in HDL metabolism. Proc Natl Acad Sci USA 94: 12610-12615, 1997.

11. Brodeur MR, Luangrath V, Bourret G, Falstrault L and Brissette L: Physiological importance of SR-BI in the in vivo metabolism of human HDL and LDL in male and female mice. J Lipid Res 46: 687-696, 2005.

12. Zanoni P, Khetarpal SA, Larach DB, Hancock-Cerutti WF, Millar JS, Cuchel M, DerOhannessian S, Kontush A, Surendran A, Saleheen D, et al: Rare variant in scavenger receptor BI raises HDL cholesterol and increases risk of coronary heart disease. Science 351: 1166-1171, 2016.

13. Rizzo G, Passeri D, De Franco F, Ciaccioli G, Donadio L, Orlandi S, Sadeghpour B, Wang XX, Jiang T, Levi M, et al: Functional characterization of the semisynthetic bile acid derivative INT-767, a dual farnesoid X receptor and TGR5 agonist. Mol Pharmacol 78: 617-630, 2010. 
14. Hambruch E, Miyazaki-Anzai S, Hahn U, Matysik S, Boettcher A, Perović-Ottstadt S, Schlüter T, Kinzel O, Krol HD, Deuschle U, et al: Synthetic farnesoid $\mathrm{X}$ receptor agonists induce high-density lipoprotein-mediated transhepatic cholesterol efflux in mice and monkeys and prevent atherosclerosis in cholesteryl ester transfer protein transgenic low-density lipoprotein receptor (-/-) mice. J Pharmacol Exp Ther 343: 556-567, 2012.

15. Zhang Y, Yin L, Anderson J, Ma H, Gonzalez FJ, Willson TM and Edwards PA: Identification of novel pathways that control farnesoid X receptor-mediated hypocholesterolemia. J Biol Chem 285: 3035-3043, 2010.

16. Chong HK, Infante AM, Seo YK, Jeon TI, Zhang Y, Edwards PA, Xie X and Osborne TF: Genome-wide interrogation of hepatic FXR reveals an asymmetric IR-1 motif and synergy with LRH-1. Nucleic Acids Res 38: 6007-6017, 2010.

17. Chao F, Gong W, Zheng Y, Li Y, Huang G, Gao M, Li J, Kuruba R, Gao X, Li S and He F: Upregulation of scavenger receptor class B type I expression by activation of FXR in hepatocyte. Atherosclerosis 213: 443-448, 2010.

18. Dong B, Young M, Liu X, Singh AB and Liu J: Regulation of lipid metabolism by obeticholic acid in hyperlipidemic hamsters. J Lipid Res 58: 350-363, 2017.

19. Repa JJ and Mangelsdorf DJ: The role of orphan nuclear receptors in the regulation of cholesterol homeostasis. Annu Rev Cell Dev Biol 16: 459-481, 2000.

20. Apfel R, Benbrook D, Lernhardt E, Ortiz MA, Salbert G and Pfahl M: A novel orphan receptor specific for a subset of thyroid hormone-responsive elements and its interaction with the retinoid/thyroid hormone receptor subfamily. Mol Cell Biol 14: 7025-7035, 1994.

21. Jakobsson T, Treuter E, Gustafsson JA and Steffensen KR: Liver $\mathrm{X}$ receptor biology and pharmacology: New pathways, challenges and opportunities. Trends Pharmacol Sci 33: 394-404, 2012.

22. Maxwell KN, Soccio RE, Duncan EM, Sehayek E and Reslow JL: Novel putative SREBP and LXR target genes identified by microarray analysis in liver of cholesterol-fed mice. J Lipid Res 44 2109-2119, 2003

23. Grefhorst A, Oosterveer MH, Brufau G, Boesjes M, Kuipers F and Groen AK: Pharmacological LXR activation reduces presence of SR-B1 in liver membranes contributing to LXR-mediated induction of HDL-cholesterol. Atherosclerosis 222: 382-389, 2012

24. Cartharius K, Frech K, Grote K, Klocke B, Haltmeier M, Klingenhoff A,Frisch M, Bayerlein M and WernerT: MatInspector and beyond: Promoter analysis based on transcription factor binding sites. Bioinformatics 21: 2933-2942, 2005.

25. Cartharius K: MatInspector: Analysing Promoters for Transcription Factor Binding Sites. The Nuts \& Bolts Series. DNA Press, 2005

26. Quandt K, Frech K, Karas H, Wingender E and Werner T: MatInd and MatInspector: New fast and versatile tools for detection of consensus matches in nucleotide sequence data. Nucleic Acids Res 23: 4878-4884, 1995.

27. Li H, Dong B, Park SW, Lee HS, Chen W and Liu J: Hepatocyte nuclear factor 1alpha plays a critical role in PCSK9 gene transcription and regulation by the natural hypocholesterolemic compound berberine. J Biol Chem 284: 28885-28895, 2009.
28. Livak KJ and Schmittgen TD: Analysis of relative gene expression data using real-time quantitative PCR and the 2(-Delta Delta C(T)) method. Methods 25: 402-408, 2001.

29. Malerød L, Juvet LK, Hanssen-Bauer A, Eskild W and Berg T: Oxysterol-activated LXRalpha/RXR induces hSR-BI-promoter activity in hepatoma cells and preadipocytes. Biochem Biophys Res Commun 299: 916-923, 2002.

30. Dong B, Kan CF, Singh AB and Liu J: High-fructose diet downregulates long-chain acyl-CoA synthetase 3 expression in liver of hamsters via impairing LXR/RXR signaling pathway. J Lipid Res 54: 1241-1254, 2013.

31. Schuetz EG, Strom S, Yasuda K, Lecureur V, Assem M, Brimer C, Lamba J, Kim RB, Ramachandran V, Komoroski BJ, et al: Disrupted bile acid homeostasis reveals an unexpected interaction among nuclear hormone receptors, transporters, and cytochrome P450. J Biol Chem 276: 39411-39418, 2001.

32. Schultz JR, Tu H, Luk A, Repa JJ, Medina JC, Li L, Schwendner S, Wang S, Thoolen M, Mangelsdorf DJ, et al: Role of LXRs in control of lipogenesis. Genes Dev 14: 2831-2838, 2000.

33. Ding L, Pang S, Sun Y, Tian Y, Yu L and Dang N: Coordinated actions of FXR and LXR in metabolism: From pathogenesis to pharmacological targets for type 2 diabetes. Int J Endocrinol 2014: 751859, 2014

34. Lu TT, Makishima M, Repa JJ, Schoonjans K, Kerr TA, Auwerx J and Mangelsdorf DJ: Molecular basis for feedback regulation of bile acid synthesis by nuclear receptors. Mol Cell 6: 507-515, 2000.

35. Matsukuma KE, Bennett MK, Huang J, Wang L, Gil G and Osborne TF: Coordinated control of bile acids and lipogenesis through FXR-dependent regulation of fatty acid synthase. J Lipid Res 47: 2754-2761, 2006.

36. Peet DJ, Turley SD, Ma W, Janowski BA, Lobaccaro JM, Hammer RE and Mangelsdorf DJ: Cholesterol and bile acid metabolism are impaired in mice lacking the nuclear oxysterol receptor LXR alpha. Cell 93: 693-704, 1998.

37. Malerød L, Sporstøl M, Juvet LK, Mousavi A, Gjøen T and Berg T: Hepatic scavenger receptor class B, type I is stimulated by peroxisome proliferator-activated receptor gamma and hepatocyte nuclear factor 4alpha. Biochem Biophys Res Commun 305: 557-565, 2003.

38. Schoonjans K, Annicotte JS, Huby T, Botrugno OA, Fayard E, Ueda Y, Chapman J and Auwerx J: Liver receptor homolog 1 controls the expression of the scavenger receptor class B type I. EMBO Rep 3: 1181-1187, 2002.

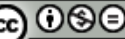

This work is licensed under a Creative Commons Attribution-NonCommercial-NoDerivatives 4.0 International (CC BY-NC-ND 4.0) License. 